\title{
Identifying Injection Drug Users at Risk of Nonfatal Overdose
}

Phillip O. Coffin, MD, MIA, Melissa Tracy, MPH, Angela Bucciarelli, MPH, Danielle Ompad, PhD,

David Vlahov, PhD, Sandro Galea, MD, DrPH

\begin{abstract}
Objectives: Drug overdose is the second leading cause of accidental deaths among U.S. adults aged 15-64 years. Emergency physicians have a unique opportunity to provide overdose prevention interventions, because habitual drug users are in frequent need of medical care. The authors evaluated associations between individual-level risk factors and experiencing an overdose in the past six months to determine which characteristics and behaviors may be most predictive of overdose.
\end{abstract}

Methods: The authors used data from a sample of street-recruited habitual drug users who participated in face-to-face interviews about overdose from November 2001 to February 2004. This analysis was restricted to 772 respondents who had been injecting for at least one year and who had injected heroin within the past two months.

Results: A total of $16.6 \%$ of participants had overdosed in the past six months. Characteristics and behaviors that were independently associated with an increased risk of a recent overdose were having had a prior overdose (odds ratio [OR], 28.58; 95\% confidence interval [CI] = 14.10 to 57.96), using cocaine/crack in the past six months (OR, 2.07; 95\% CI = 1.25 to 3.45$)$, using alcohol in the past six months (OR, 1.90; $95 \% \mathrm{CI}=1.01$ to 3.57$)$, experiencing serious withdrawal symptoms in the past two months (OR, 2.70; $95 \%$ $\mathrm{CI}=1.58$ to 4.61 ), and younger age.

Conclusions: Drug users who have previously experienced a nonfatal overdose are at very high risk of experiencing future overdoses. Further longitudinal studies are needed to identify robust predictors of overdose risk over time in habitual drug users, but these data suggest that drug users who have overdosed warrant aggressive prevention efforts such as agonist maintenance treatment or provision of take-home naloxone.

ACADEMIC EMERGENCY MEDICINE 2007; 14:616-623 @ 2007 by the Society for Academic Emergency Medicine

Keywords: drug overdose, injection drug use

$\mathrm{O}$ verdose is the second leading cause of accidental death among U.S. adults aged $15-64$ years $^{1}$ and the leading cause of death among drug users. ${ }^{2}$ Death rates from overdose have continued to climb in many regions, ${ }^{1,3}$ and more than two thirds of drug users report at least one nonfatal overdose in their lifetime. ${ }^{4}$ There were more than two million drug-related emer-

\footnotetext{
From the Center for Urban Epidemiologic Studies, New York Academy of Medicine (POC, AB, DO, DV, SG), New York, NY; Columbia University Medical Center (POC), New York, NY; Department of Epidemiology, University of Michigan School of Public Health (MT, SG), Ann Arbor, MI; and Department of Epidemiology, Columbia University Mailman School of Public Health (SG), New York, NY.

Received February 28, 2007; revision received March 27, 2007; accepted April 1, 2007.

Supported by grants DA-06534, DA-12801-S1, and R01-DA017642-01 from the National Institute on Drug Abuse.

Contact for correspondence and reprints: Phillip O. Coffin, MD, MIA; e-mail: poc2@columbia.edu.
}

gency department visits in $2004,{ }^{5}$ and nonfatal overdose is associated with substantial morbidity (e.g., physical injuries, aspiration-related lung injury and infections, seizures, and peripheral neuropathy). ${ }^{6}$

Demographic, health, and drug use characteristics and risk behaviors are associated with an increased risk of overdose. Indicators of social marginalization, including homelessness, ${ }^{7,8}$ Axis I and II mental health disorders and feelings of hopelessness, ${ }^{9-11}$ and antisocial behavior, ${ }^{12}$ have been associated with drug overdose. Overdose death is more likely following human immunodeficiency virus (HIV) seroconversion and among those with abnormal liver function, shortness of breath, and diarrhea, ${ }^{13}$ suggesting that common mechanisms of overdose death (respiratory depression and cardiac arrest $)^{14}$ may be more likely in individuals with systemic comorbidities. Length of drug use, ${ }^{4,15}$ polydrug use, ${ }^{4,16-18}$ risky drug use, ${ }^{13,15,19}$ disrupted life circumstances, ${ }^{20,21}$ and conflicts within social networks ${ }^{19}$ are associated with overdose. Risk of overdose increases with periods of reduced tolerance, including release from prison ${ }^{22}$ and naltrexone detoxification, ${ }^{23}$ while overdose risk is decreased with 
agonist maintenance therapy ${ }^{24}$; opioid metabolites in the hair of overdose decedents are far below the levels of active heroin users, ${ }^{25,26}$ suggesting periods of abstinence preceding death. Drug dependence may have a more complicated relationship with overdose, with heroin dependence possibly protecting users through increased tolerance and cocaine dependence resulting in direct toxicity. ${ }^{27}$ Few studies have looked at the breadth of potential risk factors together in one sample of habitual drug users while also controlling for history of overdose, which may be an important predictor of future overdose. ${ }^{24,28}$

Interventions for opioid overdose prevention include expanded access to opioid agonist maintenance treatment, training in rescue breathing, and prescription of take-home naloxone, the latter of which has been adopted by numerous departments of health and a growing number of medical providers. ${ }^{29-31}$ To help physicians target patients in need of overdose prevention messages, we evaluated the associations between a variety of individual-level characteristics and behaviors hypothesized to be related to overdose risk and developed a model predictive of recent overdose.

\section{METHODS}

\section{Study Design}

A cross-sectional study was conducted among current drug users to assess risk factors for recent overdose. The institutional review board at the New York Academy of Medicine approved the study, and all study subjects provided written consent at the time of the interview.

\section{Study Setting and Population}

Participants were recruited through targeted outreach techniques (described elsewhere) ${ }^{32,33}$ from selected neighborhoods in a large urban area in the United States with high proportions of minority populations from November 2001 to February 2004. Eligibility requirements included participants being 18 years of age or older and having used heroin, crack, or cocaine at least once in the two months before the interview.

\section{Study Protocol}

Structured in-person interviews were conducted in English or Spanish by trained interviewers at two stationary storefronts in central Harlem (Manhattan) and the South Bronx. Identifying information was collected from participants to ensure that individuals did not participate more than once in the study, but this information was kept separate from responses to the questionnaire to ensure anonymity, linked only by a unique identification number and stored in separate files. Data were entered and maintained electronically.

\section{Measures}

We assessed demographic characteristics (gender, age, race/ethnicity, marital status, educational attainment, and homelessness in the past six months), health status, drug use, and risk behaviors previously shown to impact overdose risk.

Overdose Experience. Consistent with investigations in Adelaide, Australia, ${ }^{17}$ and San Francisco, California, ${ }^{18}$ overdose was defined as "someone who collapses, has blue skin color, convulsions, difficulty breathing, loses consciousness, cannot be woken up, or has a heart attack or dies while using drugs." Respondents were asked if they had ever overdosed during their lifetime; those who had overdosed were asked how many times they had overdosed in the past six months, in the past year, and in their lifetime. For the purposes of this analysis, a recent overdose was defined as experiencing at least one overdose within the past six months, whereas a prior overdose was defined as experiencing at least one overdose prior to the past six months. We also asked participants if they had ever seen someone else overdose and if they had ever personally known anyone who died of a drug overdose.

Health Status. Respondents were asked to rate their overall health; responses of excellent, very good, and good were grouped together, while responses of fair and poor were grouped together to create a more clear contrast between those with better and worse self-rated health. Respondents were also asked to report their HIV status (positive, negative, or unknown). Additionally, the Medical Outcomes Survey Short-Form 36 (SF-36) was used to assess health-related quality of life. Summary scores were created for eight distinct components: physical functioning, role limitations due to physical problems, role limitations due to emotional problems, social functioning, bodily pain, vitality, general health, and mental health. Each measure was scored on a scale from 0 to 100, with higher scores indicating better health. These component scores have been repeatedly validated $^{34-36}$ and have been successfully applied to drug users in other studies. ${ }^{37}$

Drug Use and Risk Behaviors. Length of drug-using career was calculated from the participants' age of first use and last use of drugs. We also assessed the use of specific drugs in the past six months, including heroin, cocaine or crack, alcohol, and tranquilizers or benzodiazepines, and the number of types of drugs used in the past six months (marijuana, heroin, crack, cocaine, alcohol, cigarettes, methamphetamines, tranquilizers or barbiturates, hallucinogens, or other drugs). The number of types of drugs used in the past six months was categorized into two groups $(1-5, \geq 6)$ to differentiate between those who had and had not used more than the sample mean number of types of drugs.

Participants were asked about any risky practices they had engaged in at their last injection, including splitting drugs with someone else using a needle or sharing a cooker, cotton, rinse water, or needle with someone else. We also asked if participants had ever used a syringe exchange program. Finally, we asked about sexual risk behaviors in the past two months, including having a sexual partner with hepatitis, giving or receiving drugs or money for sex, using condoms less than $80 \%$ of the time with casual partners, or having more than the sample median number of sexual partners $(>1)$.

We assessed heroin and cocaine dependence using the Severity of Dependence Scale (SDS), a valid and reliable measure that assesses the degree of psychological dependence experienced by users of different types of illicit 
drugs in different settings. ${ }^{38,39}$ The SDS consists of five items: 1) "How often did you think your use of [named drug] was out of control?," 2) "How often did the prospect of going without [named drug] make you very anxious or worried?," 3) "How much did you worry about your [named drug] use?," 4) "How often did you wish you could stop?," and 5) "How difficult would you find it to stop or go without [named drug]?" Each item was scored on a four-point scale (for items 1-4: $0=$ never/ almost never, $1=$ sometimes, $2=$ often, $3=$ always $/$ nearly always; for item 5: 0 = not difficult, 1 = quite difficult, 2 = very difficult, $3=$ impossible). The total SDS score was obtained by adding the scores of all items (range, $0-15$ ), with higher total scores indicating higher levels of dependence. A test of the internal consistency of the scale among five samples demonstrated Cronbach's $\alpha$ values between 0.80 and 0.90 and correlation levels between total scores and factor scores $>0.99 .^{38}$ The SDS can be adapted to cover different types of drugs and different time periods by modifying the reference to the named drug and the specified time frame; we assessed heroin and cocaine dependence in the past year. A study reporting on the psychometric properties of the SDS in samples of heroin users showed that total SDS scores $\geq 7$ were generally indicative of severe heroin dependence. ${ }^{17,38,40}$ Another study of recent cocaine users showed that a total SDS score of $\geq 3$ discriminated best between the presence and absence of a Diagnostic and Statistical Manual of Mental Disorders, 4th Edition (DSM-IV) diagnosis of cocaine dependence. ${ }^{41}$ Consistent with these findings, we considered scores $\geq 7$ and $\geq 3$ as indicative of dependence on heroin and cocaine, respectively.

Serious withdrawal symptoms in the past two months were also assessed; examples of serious withdrawal symptoms provided to participants included stomach cramps, diarrhea, vomiting, and sweating. Finally, we asked about participation in drug treatment during the past six months, including methadone maintenance, detoxification, and other drug treatment programs including Narcotics Anonymous and therapeutic communities.

\section{Data Analysis}

This analysis was restricted to participants who reported a drug injection career of at least one year and who had injected heroin in the past two months to assess determinants of recent overdose among long-term habitual drug users rather than new or less frequent users. We restricted the analysis to heroin users to facilitate comparisons with other studies. We described the demographic characteristics, health status, drug use and risk behaviors, and overdose experience of the participants. We calculated the prevalence of recent overdose and compared characteristics of those who had and had not experienced a recent overdose. Finally, we created a multivariable logistic regression model, including all variables that significantly improved model fit using log likelihood ratio tests to build the best model predictive of recent overdose. The predictive ability of the model was assessed using the c-statistic, which corresponds to the area under the receiver operating characteristic curve. ${ }^{42}$ Higher values of the c-statistic indicate better predictive ability, with a value of 0.5 indicating no predictive ability and a value of 1.0 indicating perfect predictive ability. ${ }^{43}$ All measures described here and listed in Table 1 were considered as potential covariates for the multivariable model. Odds ratios (ORs) and 95\% confidence intervals (CIs) were calculated for all variables in the multivariable model. All analyses were performed with the SAS version 8.01 software package (SAS Institute, Inc., Cary, NC).

\section{RESULTS}

We analyzed data from 772 participants who had injected for at least one year and who had injected heroin within the past two months. Most respondents were male, 25-44 years of age, Hispanic, and unmarried, and about half had less than a high school education (Table 1). The majority reported their general health to be fair or poor; $11.5 \%$ were HIV positive, and $12.6 \%$ did not know their HIV status. Most had been using drugs for more than ten years, had used cocaine or crack and alcohol in the past six months, and reported using six or more types of drugs in the past six months. Just less than half reported at least one risky injection practice at their last injection, nearly $60 \%$ had used a needle exchange program, and about half reported risky sex in the past two months. The majority of participants were severely dependent on heroin and on cocaine, and more than one third had experienced serious withdrawal symptoms in the past two months. A history of drug treatment was common, with about $40 \%$ reporting methadone maintenance and $61 \%$ reporting detoxification in the past six months. More than two thirds of participants had ever witnessed an overdose and had personally known someone who died of an overdose.

Overall, $16.6 \%$ of respondents had experienced an overdose in the past six months (Table 1). A greater proportion of those who recently overdosed than those who did not were male, younger, and recently homeless. Recent overdose was also associated with poorer selfreported health and limitations due to physical and emotional problems, social functioning, pain, general and mental health, and use of other drugs in addition to heroin during the past six months. Those with a recent overdose were also more likely to have engaged in risky injection and sexual behaviors, were less likely to have ever used a needle exchange, and were more likely to have recently experienced serious withdrawal symptoms. Those with a recent overdose were much more likely to have witnessed an overdose, to have known someone who died of an overdose, and to have experienced a prior overdose (92.2\% vs. $33.7 \%$ ).

In a multivariable logistic regression model (Table 2), characteristics and behaviors that were associated with an increased risk of experiencing an overdose in the past six months were using cocaine/crack in the past six months (OR, 2.07; 95\% CI $=1.25$ to 3.45$)$, using alcohol in the past six months (OR, 1.90; 95\% CI = 1.01 to 3.57), experiencing serious withdrawal symptoms in the past two months (OR, 2.70; $95 \% \mathrm{CI}=1.58$ to 4.61 ), and having overdosed more than six months ago (OR, 28.58; 95\% CI $=14.10$ to 57.96 ). Younger age was associated with an increased risk of experiencing an overdose in the past six months. The c-statistic for the adjusted logistic 
Table 1

Bivariate Associations between Demographic Characteristics, Health Status, Drug Use and Risk Behaviors, and Overdose Experience, and Overdose in the Past Six Months, among Heroin Injectors

\begin{tabular}{|c|c|c|c|c|c|c|}
\hline & \multicolumn{2}{|c|}{ Total } & \multicolumn{2}{|c|}{$\begin{array}{l}\text { Overdosed in } \\
\text { Past Six Months }\end{array}$} & \multicolumn{2}{|c|}{$\begin{array}{l}\text { Did Not Overdose in } \\
\text { Past Six Months }\end{array}$} \\
\hline & $n$ & $\%$ & $n$ & $\%$ & $n$ & $\%$ \\
\hline \multicolumn{7}{|l|}{ Demographic characteristics } \\
\hline \multicolumn{7}{|l|}{ Gender } \\
\hline Male & 600 & 77.7 & 107 & 83.6 & 493 & 76.6 \\
\hline Female & 167 & 21.6 & 21 & 16.4 & 146 & 22.7 \\
\hline $45+$ & 132 & 17.1 & 15 & 11.7 & 117 & 18.2 \\
\hline $35-44$ & 296 & 38.3 & 43 & 33.6 & 253 & 39.3 \\
\hline $25-34$ & 288 & 37.3 & 55 & 43.0 & 233 & 36.2 \\
\hline $18-24$ & 56 & 7.3 & 15 & 11.7 & 41 & 6.4 \\
\hline \multicolumn{7}{|l|}{ Race/ethnicity } \\
\hline White & 88 & 11.4 & 16 & 12.5 & 72 & 11.2 \\
\hline African American & 112 & 14.5 & 22 & 17.2 & 90 & 14.0 \\
\hline Married & 115 & 14.9 & 17 & 13.3 & 98 & 15.2 \\
\hline Separated/widowed/divorced & 162 & 21.0 & 26 & 20.3 & 136 & 21.1 \\
\hline \multicolumn{7}{|l|}{ Educational attainment } \\
\hline Less than high school & 389 & 50.4 & 64 & 50.0 & 325 & 50.5 \\
\hline High school/equivalent or higher & 380 & 49.2 & 64 & 50.0 & 316 & 49.1 \\
\hline \multicolumn{7}{|l|}{ Homeless in past six months } \\
\hline No & 237 & 30.7 & 26 & 20.3 & 211 & 32.8 \\
\hline Yes & 454 & 58.8 & 90 & 70.3 & 364 & 56.5 \\
\hline \multicolumn{7}{|l|}{ Health status } \\
\hline \multicolumn{7}{|l|}{ Self-reported health } \\
\hline Excellent/very good/good & 301 & 39.0 & 39 & 30.5 & 262 & 40.7 \\
\hline Fair/poor & 463 & 60.0 & 88 & 68.8 & 375 & 58.2 \\
\hline Social functioning & & & & & & \\
\hline Bodily pain & & & & & & \\
\hline Vitality & & & & & & \\
\hline General health & & & & & & \\
\hline Mental health & & & & & & \\
\hline Drug use and risk behaviors & & & & & & \\
\hline Length of drug using career (yr) & & & & & & \\
\hline $1-4$ & 54 & 7.0 & 10 & 7.8 & 44 & 6.8 \\
\hline $5-9$ & 188 & 24.4 & 26 & 20.3 & 162 & 25.2 \\
\hline $10-14$ & 173 & 22.4 & 38 & 29.7 & 135 & 21.0 \\
\hline $15-19$ & 138 & 17.9 & 17 & 13.3 & 121 & 18.8 \\
\hline $20+$ & 219 & 28.4 & 37 & 28.9 & 182 & 28.3 \\
\hline Used cocaine or crack in past six months & & & & & & \\
\hline No & 386 & 50.0 & 42 & 32.8 & 344 & 53.4 \\
\hline Yes & 386 & 50.0 & 86 & 67.2 & 300 & 46.6 \\
\hline Used alcohol in past six months & & & & & & \\
\hline No & 223 & 28.9 & 19 & 14.8 & 204 & 31.7 \\
\hline Yes & 549 & 71.1 & 109 & 85.2 & 440 & 68.3 \\
\hline $\begin{array}{l}\text { Used tranquilizers or benzodiazepines in past } \\
\text { six months }\end{array}$ & & & & & & \\
\hline No & 566 & 73.3 & 78 & 60.9 & 488 & 75.8 \\
\hline Yes & 206 & 26.7 & 50 & 39.1 & 156 & 24.2 \\
\hline
\end{tabular}




\begin{tabular}{|c|c|c|c|c|c|c|}
\hline & \multicolumn{2}{|c|}{ Total } & \multicolumn{2}{|c|}{$\begin{array}{c}\text { Overdosed in } \\
\text { Past Six Months }\end{array}$} & \multicolumn{2}{|c|}{$\begin{array}{l}\text { Did Not Overdose in } \\
\text { Past Six Months }\end{array}$} \\
\hline & $n$ & $\%$ & $n$ & $\%$ & $n$ & $\%$ \\
\hline \multicolumn{7}{|c|}{$\begin{array}{l}\text { Number of types of drugs used in past } \\
\text { six months }\end{array}$} \\
\hline $1-5$ & 272 & 35.2 & 26 & 20.3 & 246 & 38.2 \\
\hline 6 or more & 500 & 64.8 & 102 & 79.7 & 398 & 61.8 \\
\hline \multicolumn{7}{|c|}{ Any risky injection practices at last injection $\dagger$} \\
\hline No & 440 & 57.0 & 58 & 45.3 & 382 & 59.3 \\
\hline Yes & 327 & 42.4 & 70 & 54.7 & 257 & 39.9 \\
\hline \multicolumn{7}{|c|}{ Ever used a needle exchange } \\
\hline No & 254 & 32.9 & 53 & 41.4 & 201 & 31.2 \\
\hline Yes & 458 & 59.3 & 68 & 53.1 & 390 & 60.6 \\
\hline \multicolumn{7}{|c|}{ 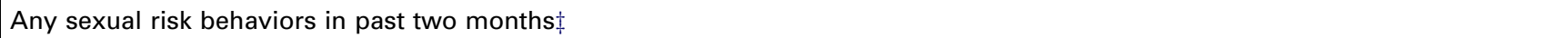 } \\
\hline No & 382 & 49.5 & 48 & 37.5 & 334 & 51.9 \\
\hline Yes & 389 & 50.4 & 80 & 62.5 & 309 & 48.0 \\
\hline \multicolumn{7}{|c|}{ Heroin dependent $\S$} \\
\hline No & 119 & 15.4 & 20 & 15.6 & 99 & 15.4 \\
\hline Yes & 651 & 84.3 & 108 & 84.4 & 543 & 84.3 \\
\hline \multicolumn{7}{|c|}{ Cocaine dependent $\|$} \\
\hline No & 114 & 14.8 & 16 & 12.5 & 98 & 15.2 \\
\hline Yes & 523 & 67.7 & 99 & 77.3 & 424 & 65.8 \\
\hline \multicolumn{7}{|c|}{ Serious withdrawal symptoms in past two months $\Phi$} \\
\hline No & 338 & 43.8 & 25 & 19.5 & 313 & 48.6 \\
\hline Yes & 434 & 56.2 & 103 & 80.5 & 331 & 51.4 \\
\hline \multicolumn{7}{|c|}{ Methadone maintenance in past six months } \\
\hline No & 371 & 48.1 & 58 & 45.3 & 313 & 48.6 \\
\hline Yes & 307 & 39.8 & 58 & 45.3 & 249 & 38.7 \\
\hline \multicolumn{7}{|c|}{ Detoxification in past six months } \\
\hline No & 292 & 37.8 & 48 & 37.5 & 244 & 37.9 \\
\hline Yes & 471 & 61.0 & 78 & 60.9 & 393 & 61.0 \\
\hline \multicolumn{7}{|c|}{ Other drug treatment in past six months } \\
\hline No & 48 & 6.2 & 10 & 7.8 & 38 & 5.9 \\
\hline Yes & 724 & 93.8 & 118 & 92.2 & 606 & 94.1 \\
\hline \multicolumn{7}{|c|}{ Overdose experience } \\
\hline \multicolumn{7}{|c|}{ Overdosed prior to past six months } \\
\hline No & 437 & 56.6 & 10 & 7.8 & 427 & 66.3 \\
\hline Yes & 335 & 43.4 & 118 & 92.2 & 217 & 33.7 \\
\hline \multicolumn{7}{|c|}{ Ever witnessed an overdose } \\
\hline No & 243 & 31.5 & 23 & 18.0 & 220 & 34.2 \\
\hline Yes & 529 & 68.5 & 105 & 82.0 & 424 & 65.8 \\
\hline \multicolumn{7}{|c|}{$\begin{array}{l}\text { Ever personally known anyone who died } \\
\text { of an overdose }\end{array}$} \\
\hline No & 238 & 30.8 & 27 & 21.1 & 211 & 32.8 \\
\hline Yes & 520 & 67.4 & 100 & 78.1 & 420 & 65.2 \\
\hline \multicolumn{7}{|c|}{$\begin{array}{l}\text { * Short Form-36 (SF-36) component scores range from } 0 \text { to } 100 \text {, with higher scores indicating better health. } \\
\dagger \text { Risky injection practices include splitting drug with needle and sharing cooker, cotton, rinse water, or needle. } \\
\ddagger \text { Risky sexual behaviors include having a sexual partner with hepatitis, giving or receiving drugs or money for sex, using condoms less than } 80 \% \text { of the } \\
\text { time with casual partners, and having more than one sexual partner. } \\
\S \text { Heroin dependence was indicated by a score of } \geq 7 \text { on the Severity of Dependence Scale. } \\
\| \text { Cocaine dependence was indicated by a score of } \geq 3 \text { on the Severity of Dependence Scale. } \\
\text { ๆSerious withdrawal symptoms include stomach cramps, diarrhea, vomiting, and sweating. }\end{array}$} \\
\hline
\end{tabular}

regression model was 0.886, demonstrating the high predictive ability of this model. ${ }^{43}$

\section{DISCUSSION}

In this cross sectional study of current heroin injectors, we found that $16.6 \%$ had experienced at least one overdose in the past six months. Controlling for other risk factors, drug users reporting a prior overdose were 29 times more likely to have a recent overdose than those not reporting a prior overdose. Other studies have demonstrated that most drug users who overdose experience multiple overdoses. ${ }^{40,44}$ Much as a prior myocardial infarction strongly predicts a current myocardial infarction in the setting of anginal chest pain, these results suggest that clinicians' most important screening question for overdose prevention may be "Have you ever overdosed before?"

We found that current heroin injectors who reported using a variety of other drugs in the past six months 
Table 2

Unadjusted and Adjusted Models Predicting Overdose in the Past Six Months, among Heroin Injectors

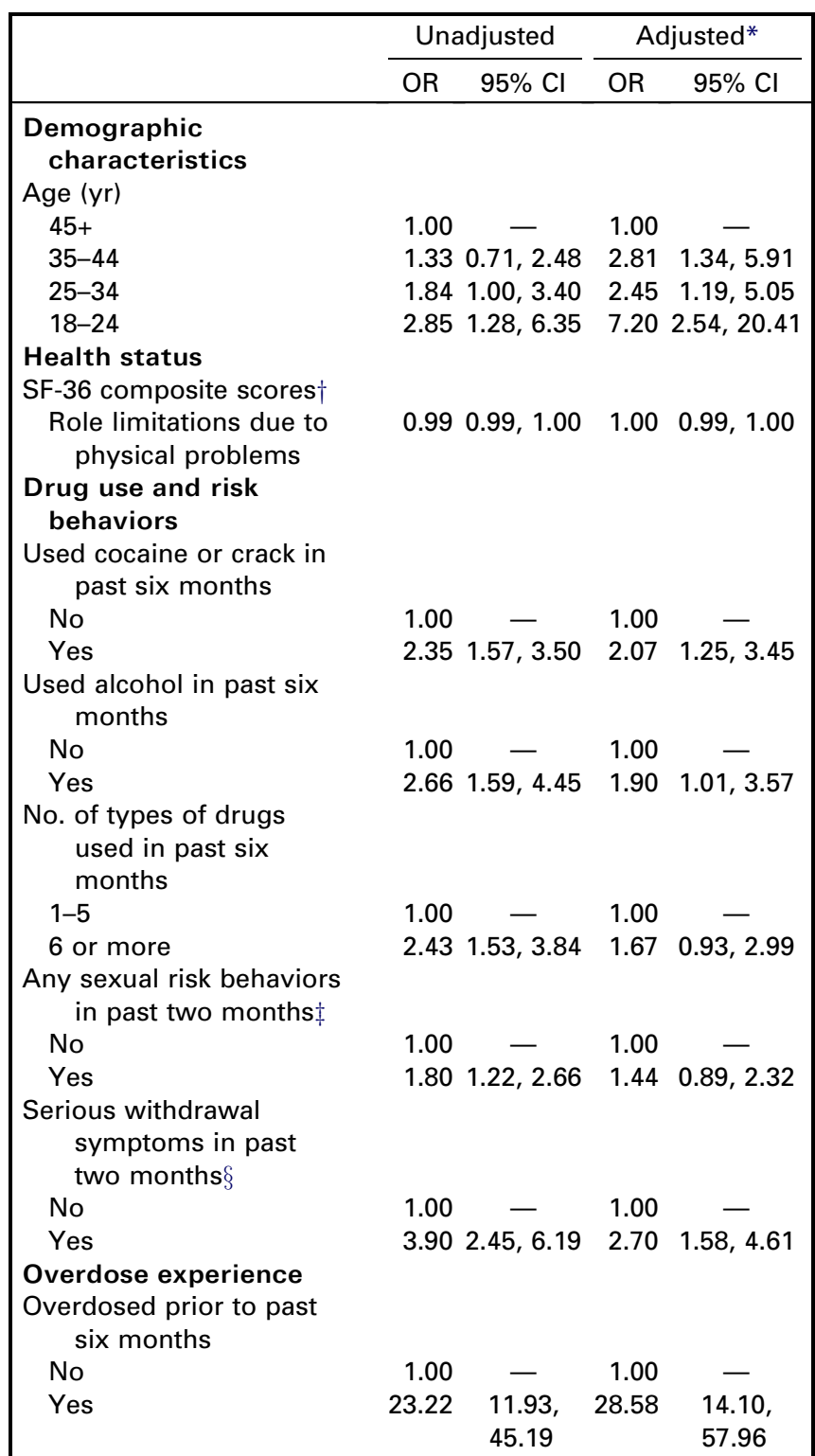

* Total of 768 participants had nonmissing values for all variables included in the adjusted model.

$\dagger$ Short Form-36 (SF-36) component scores range from 0 to 100 , with higher scores indicating better health.

$\ddagger$ Risky sexual behaviors include having a sexual partner with hepatitis, giving or receiving drugs or money for sex, using condoms less than $80 \%$ of the time with casual partners, and having more than one sexual partner.

$\S$ Serious withdrawal symptoms include stomach cramps, diarrhea, vomiting, and sweating.

were more likely to have experienced a recent overdose, consistent with earlier findings that polydrug use is a strong predictor of both fatal and nonfatal overdose. $4,15,18$ We also found that drug users who had recently experienced serious withdrawal symptoms were at greater risk for a recent overdose. These withdrawal symptoms may have resulted from voluntary or forced periods of abstinence, including incarceration or drug treatment attempts, although we did not find an independent effect of enrollment in detoxification in the past six months on the risk of recent overdose, as demonstrated in other studies. $^{23}$

In this sample, younger heroin injectors were at greatest risk of experiencing a recent overdose. Although this finding has been replicated in at least one other study, ${ }^{7}$ most studies have indicated greater risk of overdose among older users. ${ }^{4,15,45}$ In these studies, age is often reflective of length of drug-using career, with overdose risk increasing as length of drug-using career increases ${ }^{4}$; this analysis of recent overdose captured current rather than cumulative risk. It is also possible that in this sample, younger age reflected unmeasured exposures to social network characteristics that may increase risk of overdose, including larger networks and conflicts with network members ${ }^{19}$ or other unmeasured risk behaviors. $^{46}$

\section{LIMITATIONS}

These results must be considered preliminary due to several limitations. These data are not prospective, therefore the inferences that can be drawn regarding the predictive nature of characteristics and behaviors for overdose are limited. In addition, the timelines of some variables differ, with some referring to the most recent injection or behavior within the past two or six months. Although these most recent behaviors likely reflect consistent conditions and risk behaviors over the full duration of the relevant time period, because drug use and risk behaviors tend to be relatively consistent over time, ${ }^{47}$ this is not possible to demonstrate definitively. Intervieweradministered surveys are subject to social desirability bias, although other studies among drug users have demonstrated high validity in self-reported drug use and risk behaviors. ${ }^{47-49}$ Recall bias may also be present in surveys, although this should be minimized by the focus on recent events. Some measures were used as proxies for the underlying measures of interest; for example, we did not have a direct measure of drug tolerance. Our measures of physical and mental health were limited to a general picture of perceived health and may not detect asymptomatic disease that may nonetheless contribute to risk of overdose. Finally, we assessed factors associated with recent nonfatal overdose; risk factors for fatal overdose may be different.

\section{CONCLUSIONS}

The strongest independent predictor of a nonfatal overdose among habitual heroin injectors was having had a prior overdose. Emergency physicians, often present during overdose management and revival, may have a unique opportunity to prevent future overdoses through, for example, referral to agonist maintenance treatment, delivery of overdose prevention education, or novel interventions such as prescription of take-home naloxone. ${ }^{30}$ Prospective studies are needed to generate a rigorous model to predict future overdose risk among drug users. 


\section{References}

1. Centers for Disease Control and Prevention. Unintentional poisoning deaths-United States, 1999-2004. MMWR. Morb Mortal Wkly Rep. 2007; 56(5):93-6.

2. Bargagli AM, Sperati A, Davoli M, Forastiere F. Mortality among problem drug users in Rome: an 18-year follow-up study, 1980-97. Addiction. 2001; 96:1455-63.

3. Alexander JL, Burton JH, Bradshaw JR, Colin F. Suspected opioid-related emergency medical services encounters in a rural state, 1997-2002. Prehosp Emerg Care. 2004; 8:427-30.

4. Darke S, Ross J, Hall W. Overdose among heroin users in Sydney, Australia: I. Prevalence and correlates of non-fatal overdose. Addiction. 1996; 91: 405-11.

5. Substance Abuse and Mental Health Services Administration. Drug abuse warning network, 2004: national estimates of drug-related emergency department visits. Rockville, MD: Substance Abuse and Mental Health Services Administration, publication no. 06-4143, 2006.

6. Warner-Smith M, Darke S, Day C. Morbidity associated with non-fatal heroin overdose. Addiction. 2002; 97:963-7.

7. Seal KH, Kral AH, Gee L, et al. Predictors and prevention of nonfatal overdose among street-recruited injection heroin users in the San Francisco Bay Area, 1998-1999. Am J Public Health. 2001; 91:1842-6.

8. O'Driscoll PT, McGough J, Hagan H, Thiede H, Critchlow C, Alexander ER. Predictors of accidental fatal drug overdose among a cohort of injection drug users. Am J Public Health. 2001; 91:984-7.

9. Tobin KE, Latkin CA. The relationship between depressive symptoms and nonfatal overdose among a sample of drug users in Baltimore, Maryland. J Urban Health. 2003; 80:220-9.

10. Mills KL, Teesson M, Ross J, Darke S, Shanahan M. The costs and outcomes of treatment for opioid dependence associated with posttraumatic stress disorder. Psychiatr Serv. 2005; 56:940-5.

11. Darke S, Ross J, Williamson A, Teesson M. The impact of borderline personality disorder on 12-month outcomes for the treatment of heroin dependence. Addiction. 2005; 100:1121-30.

12. Burns JM, Martyres RF, Clode D, Boldero JM. Overdose in young people using heroin: Associations with mental health, prescription drug use and personal circumstances. Med J Aust. 2004; 181:S25-8.

13. Wang C, Vlahov D, Galai N, et al. The effect of HIV infection on overdose mortality. AIDS. 2005; 19:935-42.

14. White JM, Irvine RJ. Mechanisms of fatal opioid overdose. Addiction. 1999; 94:961-72.

15. Darke S, Hall W. Heroin overdose: research and evidence-based intervention. J Urban Health. 2003; 80:189-200.

16. Coffin PO, Galea S, Ahern J, Leon AC, Vlahov D, Tardiff $\mathrm{K}$. Opiates, cocaine and alcohol combinations in accidental drug overdose deaths in New York City, 1990-98. Addiction. 2003; 98:739-47.

17. McGregor C, Darke S, Ali R, Christie P. Experience of non-fatal overdose among heroin users in Adelaide,
Australia: circumstances and risk perceptions. Addiction. 1998; 93:701-11.

18. Ochoa KC, Hahn JA, Seal KH, Moss AR. Overdosing among young injection drug users in San Francisco. Addict Behav. 2001; 26:453-60.

19. Latkin CA, Hua W, Tobin K. Social network correlates of self-reported non-fatal overdose. Drug Alcohol Depend. 2004; 73:61-7.

20. Neale J, Robertson M. Recent life problems and nonfatal overdose among heroin users entering treatment. Addiction. 2005; 100:168-75.

21. Heale P, Dietze P, Fry C. Intentional overdose among heroin overdose survivors. J Urban Health. 2003; 80: 230-7.

22. Seymour A, Oliver JS, Black M. Drug-related deaths among recently released prisoners in the Strathclyde region of Scotland. J Forensic Sci. 2000; 45:649-54.

23. Digiusto E, Shakeshaft A, Ritter A, O’Brien S, Mattick RP. Serious adverse events in the Australian national evaluation of pharmacotherapies for opioid dependence (NEPOD). Addiction. 2004; 99:450-60.

24. Darke S, Williamson A, Ross J, Teesson M. Non-fatal heroin overdose, treatment exposure and client characteristics: findings from the Australian Treatment Outcome Study (ATOS). Drug Alcohol Rev. 2005; 24:425-32.

25. Tagliaro F, De Battisti Z, Smith FP, Marigo M. Death from heroin overdose: findings from hair analysis. Lancet. 1998; 351:1923-5.

26. Darke S, Hall W, Kaye S, Ross J, Duflou J. Hair morphine concentrations of fatal heroin overdose cases and living heroin users. Addiction. 2002; 97:977-84.

27. Galea S, Nandi A, Coffin PO, Vlahov D. Heroin and cocaine dependence and the risk of accidental nonfatal drug overdose. J Addict Dis. 2006; 25:79-87.

28. Stewart D, Gossop M, Marsden J. Reductions in non-fatal overdose after drug misuse treatment: results from the national treatment outcome research study (NTORS). J Subst Abuse Treat. 2002; 22:1-9.

29. Dietze P, Cantwell K, Burgess S. Bystander resuscitation attempts at heroin overdose: does it improve outcomes? Drug Alcohol Depend. 2002; 67:213-8.

30. Baca CT, Grant KJ. Take-home naloxone to reduce heroin death. Addiction. 2005; 100:1823-31.

31. Davidson P. Design and Implementation of the OOPS Emergency Department Project: Review to December 1998. Australia: Commonwealth Department of Health and Aged Care, 1999.

32. Diaz T, Des Jarlais DC, Vlahov D, et al. Factors associated with prevalent hepatitis C: Differences among young adult injection drug users in lower and upper Manhattan, New York City. Am J Public Health. 2001; 91:23-30.

33. Diaz T, Vlahov D, Greenberg B, Cuevas Y, Garfein R. Sexual orientation and HIV infection prevalence among young Latino injection drug users in Harlem. J Womens Health Gend Based Med. 2001; 10:371-80.

34. Ware JE Jr, Sherbourne CD. The MOS 36-item shortform health survey (SF-36). I. conceptual framework and item selection. Med Care. 1992; 30:473-83.

35. Ware JE Jr, Gandek B, Kosinski M, et al. The equivalence of SF-36 summary health scores estimated using standard and country-specific algorithms in 
10 countries: results from the IQOLA project. International Quality of Life Assessment. J Clin Epidemiol. 1998; 51:1167-70.

36. McHorney CA, Ware JE Jr, Raczek AE. The MOS 36-item short-form health survey (SF-36): II. Psychometric and clinical tests of validity in measuring physical and mental health constructs. Med Care. 1993; 31: 247-63.

37. Falck RS, Wang J, Siegal HA, Carlson RG. Longitudinal application of the medical outcomes study 36-item short-form health survey with not-in-treatment crackcocaine users. Med Care. 2000; 38:902-10.

38. Gossop M, Darke S, Griffiths P, et al. The severity of dependence scale (SDS): Psychometric properties of the SDS in English and Australian samples of heroin, cocaine and amphetamine users. Addiction. 1995; 90: 607-14.

39. Gossop M, Best D, Marsden J, Strang J. Test-retest reliability of the severity of dependence scale [letter]. Addiction. 1997; 92:353.

40. Gossop M, Griffiths P, Powis B, Williamson S, Strang J. Frequency of non-fatal heroin overdose: survey of heroin users recruited in non-clinical settings. BMJ. 1996; 313:402.

41. Kaye S, Darke S. Determining a diagnostic cut-off on the severity of dependence scale (SDS) for cocaine dependence. Addiction. 2002; 97:727-31.
42. Hanley JA, McNeil BJ. The meaning and use of the area under a receiver operating characteristic (ROC) curve. Radiology. 1982; 143:29-36.

43. Harrell FE Jr. Regression modeling strategies, with applications to linear models, logistic regression, and survival analysis. New York: Springer, 2000.

44. Powis B, Strang J, Griffiths P, et al. Self-reported overdose among injecting drug users in London: extent and nature of the problem. Addiction. 1999; 94: 471-8.

45. Darke S, Zador D. Fatal heroin 'overdose': a review. Addiction. 1996; 91:1765-72.

46. Kral AH, Lorvick J, Edlin BR. Sex- and drug-related risk among populations of younger and older injection drug users in adjacent neighborhoods in San Francisco. J Acquir Immune Defic Syndr. 2000; 24: $162-7$

47. Darke S. Self-report among injecting drug users: a review. Drug Alcohol Depend. 1998; 51:253-63.

48. Dowling-Guyer S, Johnson ME, Fisher DG, et al. Reliability of drug users' self-reported HIV risk behaviors and validity of self-reported recent drug use. Assessment. 1994; 1:383-92.

49. Nyamithi A, Leake B, Longshore D, Gelberg L. Reliability of homeless women's reports: concordance between hair assay and self report of cocaine use. Nurs Res. 2001; 50:165-71.

\title{
REFLECTIONS
}

\author{
They Go Back
}

\author{
Black eyes and guarded looks \\ Really quite pretty \\ The girl explained: \\ I walked into a wall \\ tripped up, fell down \\ They are not convinced \\ Her man professes love \\ with iron fists. \\ Police are called \\ Reports completed, papers filed \\ As she protests \\ It makes no sense \\ Exasperates them all \\ One thing is understood: \\ Before the ink is dry \\ She'll go back \\ They always do
}

